\title{
Transport of short-lived species into the Tropical Tropopause Layer
}

\author{
M. J. Ashfold ${ }^{1}$, N. R. P. Harris ${ }^{1}$, E. L. Atlas ${ }^{2}$, A. J. Manning ${ }^{3}$, and J. A. Pyle ${ }^{1,4}$ \\ ${ }^{1}$ Department of Chemistry, University of Cambridge, Cambridge, UK \\ ${ }^{2}$ Rosenstiel School of Marine and Atmospheric Science, University of Miami, Miami, Florida, USA \\ ${ }^{3}$ Met Office, Exeter, UK \\ ${ }^{4}$ National Centre for Atmospheric Science, UK \\ Correspondence to: M. J. Ashfold (mja63@cam.ac.uk)
}

Received: 13 November 2011 - Published in Atmos. Chem. Phys. Discuss.: 6 January 2012

Revised: 1 May 2012 - Accepted: 26 May 2012 - Published: 19 July 2012

\begin{abstract}
We use NAME, a trajectory model, to investigate the routes and timescales over which air parcels reach the tropical tropopause layer (TTL). Our aim is to assist the planning of aircraft campaigns focussed on improving knowledge of such transport. We focus on Southeast Asia and the Western Pacific which appears to be a particularly important source of air that enters the TTL. We first study the TTL above Borneo in November 2008, under neutral El Niño/Southern Oscillation (ENSO) conditions. Air parcels (trajectories) arriving in the lower TTL (below $\sim 15 \mathrm{~km}$ ) are most likely to have travelled from the boundary layer (BL; $<1 \mathrm{~km}$ ) above the West Pacific. Few air parcels found above $\sim 16 \mathrm{~km}$ travelled from the $\mathrm{BL}$ in the previous 15 days. We then perform similar calculations for moderate El Niño (2006) and La Niña (2007) conditions and find yearto-year variability consistent with the phase of ENSO. Under El Niño conditions fewer air parcels travel from the BL to the TTL above Borneo. During the La Niña year, more air parcels travel from the BL to the mid and upper TTL (above $\sim 15 \mathrm{~km}$ ) than in the ENSO-neutral year, and again they do so from the BL above the West Pacific. We also find intra-month variability in all years, with day-to-day differences of up to an order of magnitude in the fraction of an idealised shortlived tracer travelling from the BL to the TTL above Borneo. These calculations were performed as a prelude to the SHIVA field campaign, which took place in Borneo during November 2011. So finally, to validate our approach, we consider measurements made in two previous campaigns. The features of vertical profiles of short-lived species observed in the TTL during CR-AVE and TC4 are in broad agreement with calculated vertical profiles of idealised short-lived tracers. It will require large numbers of observations to fully describe the
\end{abstract}

statistical distribution of short-lived species in the TTL. This modelling approach should prove valuable in planning flights for the long-duration aircraft now capable of making such measurements.

\section{Introduction}

Catalytic cycles involving bromine are known to destroy ozone in the lower stratosphere (Yung et al., 1980; Salawitch et al., 2005). The major sources of stratospheric bromine are currently the family of halons, which have lifetimes of up to $65 \mathrm{yr}$, and methyl bromide $\left(\mathrm{CH}_{3} \mathrm{Br}\right)$, which has a lifetime of $0.8 \mathrm{yr}$ (Montzka and Reimann, 2011). However, measurements of these longer-lived compounds in the upper troposphere (e.g. Laube et al., 2008), and of subsequently produced bromine monoxide in the stratosphere (e.g. Dorf et al., 2006) suggest that an additional bromine source of $\sim 5 \mathrm{ppt}$ must exist. Various recent modelling studies (e.g. Gettelman et al., 2009; Hossaini et al., 2010; Liang et al., 2010) have shown that so-called very short-lived substances (VSLS), usually defined as having mean atmospheric lifetimes of less than 6 months, could provide a significant fraction of this extra source of bromine to the stratosphere.

These VSLS, including bromoform $\left(\mathrm{CHBr}_{3}\right)$ and dibromomethane $\left(\mathrm{CH}_{2} \mathrm{Br}_{2}\right)$, are largely emitted by macroalgae in coastal regions and by phytoplankton (Quack and Wallace, 2003; Paul and Pohnert, 2011). To reach the stratosphere in appreciable quantities VSLS must be emitted where transport from the surface towards the stratosphere occurs over timescales shorter than their lifetimes. In practice, this means the tropics, where deep convection can lift air quickly 
in to the primary gateway to the stratosphere, the tropical tropopause layer (TTL) (e.g. Fueglistaler et al., 2009). A range of models suggest that emissions from Southeast Asia and the tropical Western Pacific are more likely to enter the TTL than emissions from other tropical longitudes (e.g. Levine et al., 2007; Aschmann et al., 2009; Hosking et al., 2010; Pisso et al., 2010).

There remains, however, uncertainty in each of the following aspects of this problem: (1) the size, and the distribution of VSLS sources; (2) the rate and paths of transport from surface to stratosphere; and (3) the chemical and physical mechanisms by which VSLS and their products are removed while travelling towards the stratosphere. To reduce these uncertainties remains an important goal, not least because it is conceivable that each of these processes are affected by changes in climate over the coming century. Further motivation is provided by the introduction of additional "anthropogenic" sources of VSLS. Commercial cultivation of macroalgae has become an increasingly important part of many Asian economies, with global production growing at an average annual rate of $7.7 \%$ since 1970 (FAO Fisheries and Aquaculture Department, 2010). In addition, the feasibility of using microalgae as a biofuel is receiving increasing attention (e.g. Mata et al., 2010).

As VSLS have inhomogeneous sources and short lifetimes it is unsurprising that both surface (e.g. Yokouchi et al., 2005; Butler et al., 2007; O'Brien et al., 2009; Pyle et al., 2011) and airborne (e.g. Schauffler et al., 1999; Laube et al., 2008; Hossaini et al., 2010; Park et al., 2010) measurements of these compounds exhibit significant variability. And because observations are sparse in both space and time, it is questionable how representative of the larger-scale reality any particular set of measurements might be. In this study we focus on the modelling techniques which might be used to understand observations in the troposphere and the TTL, and to help design measurement strategies. For example, we should not expect that relatively coarse resolution global models will simulate the variable concentrations of VSLS observed along a flight track, although in some average sense they need to perform well in this crucial area. Furthermore, although the fine structure of VSLS observations may be beyond even the scales resolved by many limited area models, it is important to try to develop validation strategies for the whole range of models being used to study atmospheric composition and transport through the TTL.

In Sect. 2 we use an air parcel trajectory model to address the following questions relevant to the composition of the TTL, with an emphasis on the variability one might expect to observe: (1) What is the spectrum of time-scales over which air parcels travel from the boundary layer to higher altitudes? (2) Where has air in the TTL travelled from and, particularly, most recently been subject to boundary layer emissions? (3) How do the answers to the previous questions change over the duration of a typical aircraft campaign (a month), and in different years (and phases of the El Niño/Southern Oscil- lation (ENSO))? We then relate our answers to these three questions to the hypothetical abundance of a VSLS such as $\mathrm{CHBr}_{3}$ in the TTL and consider the use of this model in deriving aircraft measurement strategies.

The trajectory calculations and analysis are in part motivated by our involvement in the SHIVA campaign, which was based in Malaysian Borneo, and took place in November 2011 (see http://shiva.iup.uni-heidelberg.de/ for details) but we believe the calculations have a general relevance. Of course, they are based on a model which is inevitably an incomplete description of the atmosphere; some attempt at validation is essential. Accordingly, in Sect. 4 we compare the model behaviour with VSLS measurements made in the TTL over Central America (introduced briefly in Sect. 3). Section 5 contains some conclusions.

\section{Trajectory calculations for the TTL above Borneo}

Trajectory studies relevant to VSLS have often focussed on the details of transport through the TTL to the stratosphere (e.g. Fueglistaler et al., 2004; Levine et al., 2008; Krüger et al., 2008, 2009; Schofield et al., 2011). However, our interest is in the use of models, and field measurements, to explore the preceding transport pathways from the boundary layer (i.e. emission) to the TTL. Deep cumulus convection is expected to be an important component of such transport. However, it is not possible to resolve individual up- and down-drafts associated with convective clouds in present-day global models. Parameterisations have therefore been developed which aim, in a chemical sense, to simulate the net effect of convection in vertically redistributing material. Tost et al. (2010) have shown that different parameterisations of convection lead to substantial differences in simulated chemical profiles in an Eulerian model. In a comparison of vertical transport of idealised tracers in a range of Eulerian models, Hoyle et al. (2011) reported a substantial impact on calculated tracer profiles when different convective parameterisations were employed (see also earlier work by Lawrence and Rasch, 2005). In a Lagrangian representation, Pisso et al. (2010) added a parameterisation of deep convection to their model and found that the fraction of an idealised VSLS emitted at the surface, that then goes on to reach the upper TTL, increased by up to an order of magnitude. It is clear then, that the influence of deep convection on atmospheric composition and chemistry remains an active area of research, with many remaining uncertainties. However, Heyes et al. (2009) have recently shown that, in a region of significant convective activity, the composition of the out-of-cloud TTL can be usefully interpreted with the aid of trajectories calculated with wind fields that are consistent with large-scale convection, but without an explicit parameterisation of convection. We therefore adopt a similar approach in the work outlined below. 
In this study, we have used NAME, the UK Met Office dispersion model (see Jones et al., 2007), to calculate back trajectories. NAME uses three-dimensional wind fields from the operational output of the UK Met Office Unified Model (Davies et al., 2005). These winds have a horizontal resolution of $0.5625^{\circ}$ longitude by $0.375^{\circ}$ latitude (approximately 60 by $40 \mathrm{~km}$ in the tropics) and are on 31 vertical levels up to $\sim 19 \mathrm{~km}$. To reiterate, it is clear that winds with this resolution will not capture individual convective cells, but the parameterisation of convection within the UM aims to model net vertical transport over the relatively large areas that we consider. A random walk technique is used to model the effects of turbulence on the trajectories (for details, see Morrison and Webster, 2005).

The initial focus is on the TTL over northern Borneo. There are a number of reasons why this is a particularly interesting area to study. First, Borneo occupies a central location in Southeast Asia; in Sect. 1 we noted that this is a part of the world where VSLS emissions might be particularly likely to reach the TTL. Second, because of the region's importance, the SHIVA field campaign, which focussed on improving our knowledge of the role of VSLS in atmospheric chemistry, took place here during November 2011. Our calculations are aimed at flight planning and data interpretation for this type of campaign. And third, we have made measurements of a range of VSLS at 2 surface sites in Northern Borneo since mid-2008. Early results have been reported by Gostlow et al. (2010) and Pyle et al. (2011) and surface concentrations are therefore becoming relatively well understood. However, at the time of writing, there are no measurements of VSLS in the TTL in this region, and this section is therefore a theoretical study. We aim, though, to raise issues relevant to any tropical field campaign that may occur in the future.

SHIVA took place in November and here we consider the Novembers of 2006, 2007 and 2008. These months were at the beginning of, respectively, moderate El Niño, moderate La Niña, and ENSO-neutral Northern Hemisphere (NH) winters. November 2008 is therefore used as a "base case" and contrasted with the Novembers of 2006 and 2007. We release back trajectories from a three-dimensional domain bounded by $109-119^{\circ} \mathrm{E}, 0-8^{\circ} \mathrm{N}$ and $7-18 \mathrm{~km}$. To allow both monthly averages (in Sects. 2.1 and 2.2) and day-to-day variability (Sect. 2.3) to be assessed, 10000 trajectories are started continuously during each day of each November from each $1 \mathrm{~km}$ altitude band. The trajectories travel for 15 days and their positions are recorded at 6-hourly intervals. In the subsequent analysis we have selected two trajectory starting altitudes to examine in detail. First, $12-13 \mathrm{~km}$, which might be representative of TTL entry conditions, and is a typical flight ceiling for "conventional" research aircraft. Second, 15-16 km, which is an intermediate TTL altitude and is easily within range of specialised "higher flyers" such as NASA's WB57, ER-2 and Global Hawk aircraft. We consider altitudes at which aircraft might fly rather than using any particular definition of the TTL in which absolute altitude might vary year-to-year (e.g. the cold point as an upper boundary; see Gettelman and Forster, 2002).

\subsection{Time-scales and locations of surface to TTL transport}

The first two questions we posed in Sect. 1 related to the time-scales, and the preferential locations, for transport from the boundary layer to the TTL. To begin to address these questions for our region of interest, the maps in Fig. 1 show where trajectories started above Borneo in November 2008 between $12-13 \mathrm{~km}$, and $15-16 \mathrm{~km}$, first cross $1 \mathrm{~km}$ and $4 \mathrm{~km}$. To the right of each map is a probability distribution of the time it takes for trajectories to cross the altitude in question.

Figure 1a shows that back trajectories which started between $12-13 \mathrm{~km}$ are most likely to cross $4 \mathrm{~km}$ after $3-5$ days, and after $\sim 6$ days half of the trajectories have crossed $4 \mathrm{~km}$. The most likely location for crossing $4 \mathrm{~km}$ is $\sim 20^{\circ} \mathrm{E}$ of the region where the trajectories start. The situation is similar when crossing altitudes of $5 \mathrm{~km}$ and $6 \mathrm{~km}$ are considered (not shown). So in this case study the modelled composition of the lower TTL above Borneo (between 12-13 km) is expected to be strongly influenced by the composition of the midtroposphere $(4-6 \mathrm{~km}) \sim 5$ days beforehand; this timescale is significantly shorter than the local lifetime of a VSLS such as $\mathrm{CHBr}_{3}$.

Figure $1 \mathrm{~b}$ shows that around half of the trajectories that started between $12-13 \mathrm{~km}$ crossed $1 \mathrm{~km}$ within 15 days and it is most likely that a trajectory will cross $1 \mathrm{~km}$ after $\sim 7$ days. The most likely crossing location is a narrow-latitude band further to the east, which suggests that emissions in the Western Pacific might be particularly important for the lowest part of the TTL over Borneo.

Figure 1c and d consider trajectories started between 15$16 \mathrm{~km}$, and contain many of the features found in plots a and $\mathrm{b}$. A significant fraction of trajectories, more than half, cross $4 \mathrm{~km}$ within the 15 day calculation, and they are most likely to do so $\sim 20-30^{\circ} \mathrm{E}$ of their starting location. Approximately a quarter of trajectories starting in this altitude range cross $1 \mathrm{~km}$; this is half as many as do so when started between $12-13 \mathrm{~km}$. The boundary layer in the Western Pacific region also appears to be an important source of air for the TTL at $15-16 \mathrm{~km}$ above Borneo.

The previous analysis does not tell us about the details of transport between the boundary layer and the TTL, and does not account for those trajectories that do not reach either $1 \mathrm{~km}$ or $4 \mathrm{~km}$ within 15 days. More detail is given in Fig. 2 which shows, for trajectories starting in $1 \mathrm{~km}$ intervals between 12 $18 \mathrm{~km}$ in November 2008, the probability that a trajectory is at a particular altitude as it travels backwards in time.

In Fig. 2a, for trajectories starting between $12-13 \mathrm{~km}$, a small fraction resides in the lowest $1 \mathrm{~km}$ after 1 day, but it is not until $\sim 7$ days that $10 \%$ of the trajectories are below $1 \mathrm{~km}$. Note that more than $10 \%$ of trajectories will have crossed $1 \mathrm{~km}$ within these 7 days; Fig. $1 \mathrm{~b}$ shows that it takes 

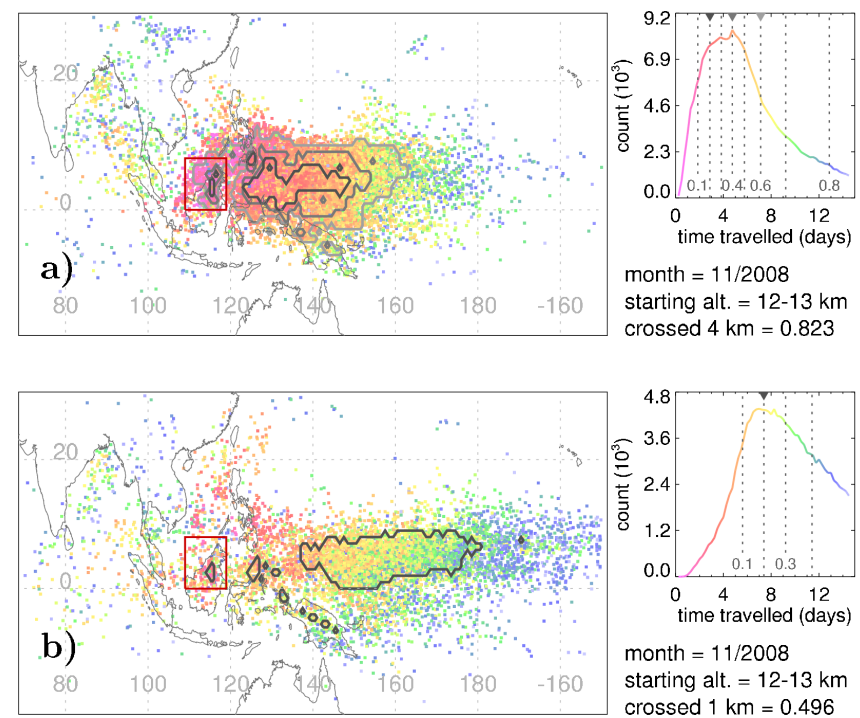
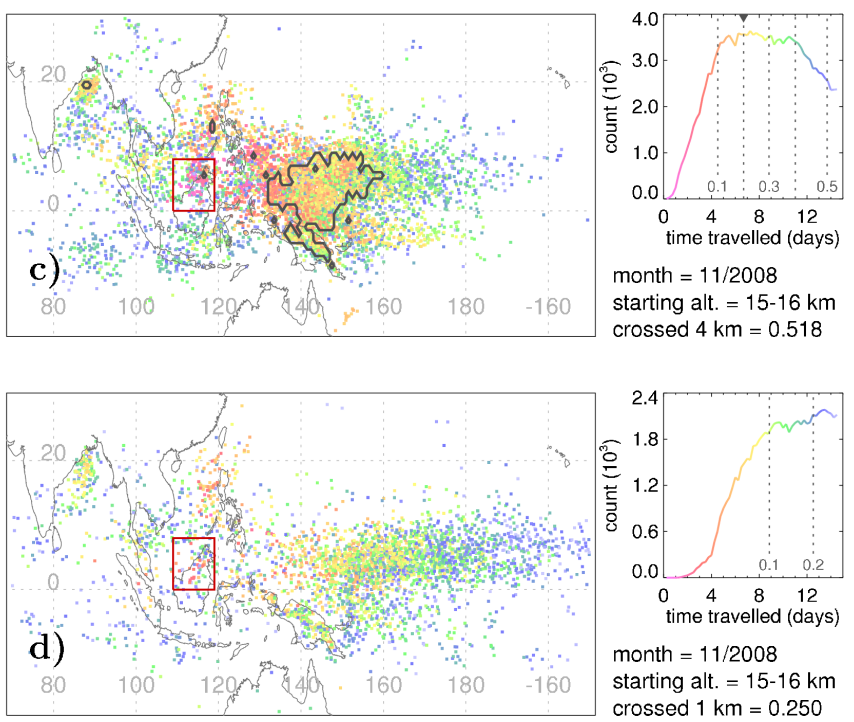

Fig. 1. The maps show trajectory crossing locations. Back trajectories start at random within the red rectangle throughout November 2008. In (a) and (b) trajectories start between 12-13 km, in (c) and (d) trajectories start between 15-16 km. The coloured dots in (a) and (c) show where a random sample of $5 \%$ of trajectories first crossed $4 \mathrm{~km}$ above the surface, while (b) and (d) show the same for $1 \mathrm{~km}$. The dots are coloured by the time taken to cross either 1 or $4 \mathrm{~km}$. To the right of each map are probability distributions of crossing times $(6 \mathrm{~h}$ bins), where the colour of the line relates to the colours of the dots in the map. Successive deciles are marked with dashed grey lines, and the total fraction of trajectories that cross within 15 days is noted below. Where there are sufficient trajectories, the grey down-turned triangles mark the fraction crossing within the contour of the same colour on the map.

only $\sim 5.5$ days for $10 \%$ of trajectories to cross $1 \mathrm{~km}$. The difference is due to multiple crossings of $1 \mathrm{~km}$ by some trajectories. Following the 10th percentile lines in Fig. 2 (particularly Fig. 2a-d, representing trajectories started between $12-16 \mathrm{~km}$ ) also shows that transport from the boundary layer to $\sim 4 \mathrm{~km}$ can take as long as transport between $4 \mathrm{~km}$ and the TTL. So, to reiterate, these trajectories suggest that measurements made in the TTL might bear a significantly clearer signature of air previously measured at $\sim 4 \mathrm{~km}$ than of air previously measured at $\sim 1 \mathrm{~km}$.

In Fig. 2 there are two dominant trajectory origins. In Fig. 2a (starting altitude $12-13 \mathrm{~km}$ ) the majority of trajectories originate in the lower troposphere, and in Fig. $2 \mathrm{f}$ (starting altitude $17-18 \mathrm{~km}$ ) the majority of trajectories travel approximately horizontally within the upper TTL. An interesting intermediate case is Fig. $2 \mathrm{~d}$ (starting altitude $15-16 \mathrm{~km}$ ) where a transition between these two regimes occurs.

The first population of trajectories, originating in the lower troposphere, are typically transported from the Western Pacific region (see Fig. 1). The second population of trajectories, originating in the TTL, are typically transported from above the Asian subcontinent and follow an anti-cyclonic path to arrive above Borneo from the northeast (not shown). The trajectories presented in Figs. 1 and 2 therefore show that the TTL above Borneo is likely to be composed of two distinct types of air mass. They also suggest that it might not be possible to link measurements made at the surface in Borneo to measurements made in the TTL directly overhead.
Of course local individual convective events, which will also undoubtedly contribute to the TTL above Borneo to some degree, are not explicitly represented within our calculations.

\subsection{Interannual variability}

The third question we posed in Sect. 1 relates to the sensitivity of transport to the year studied. We now consider interannual differences by comparing the calculations for November 2008 with similar calculations for the Novembers of 2006 (an El Niño NH winter) and 2007 (La Niña). By examining only three years we can not assess the entire range of year-toyear variability, but we can begin to characterise the different atmospheric conditions that hypothetical measurement campaigns in each of these years might encounter.

An indication that there are notable differences between these three years is provided by Fig. 3, which shows the fraction of back trajectories, started at various altitudes, that within 15 days cross $1 \mathrm{~km}$ and $4 \mathrm{~km}$ above the surface. In 2008, approximately half of back trajectories starting below $13 \mathrm{~km}$ cross $1 \mathrm{~km}$ within 15 days (also shown in Fig. 1b). As the starting altitude increases from 13 to $18 \mathrm{~km}$, this fraction falls rapidly to $\sim 0.05$. The fraction of trajectories reaching $4 \mathrm{~km}$ falls from a reasonably steady $\sim 0.85$ for starting altitudes up to $13 \mathrm{~km}$, to $\sim 0.1$ at $18 \mathrm{~km}$. During the $2006 \mathrm{El}$ Niño many fewer trajectories reach either $1 \mathrm{~km}$ or $4 \mathrm{~km}$, regardless of their starting altitudes. In contrast, the $2007 \mathrm{La}$ Niña is more similar to the neutral base case. The number of trajectories reaching $1 \mathrm{~km}$ in 2007 is marginally smaller 

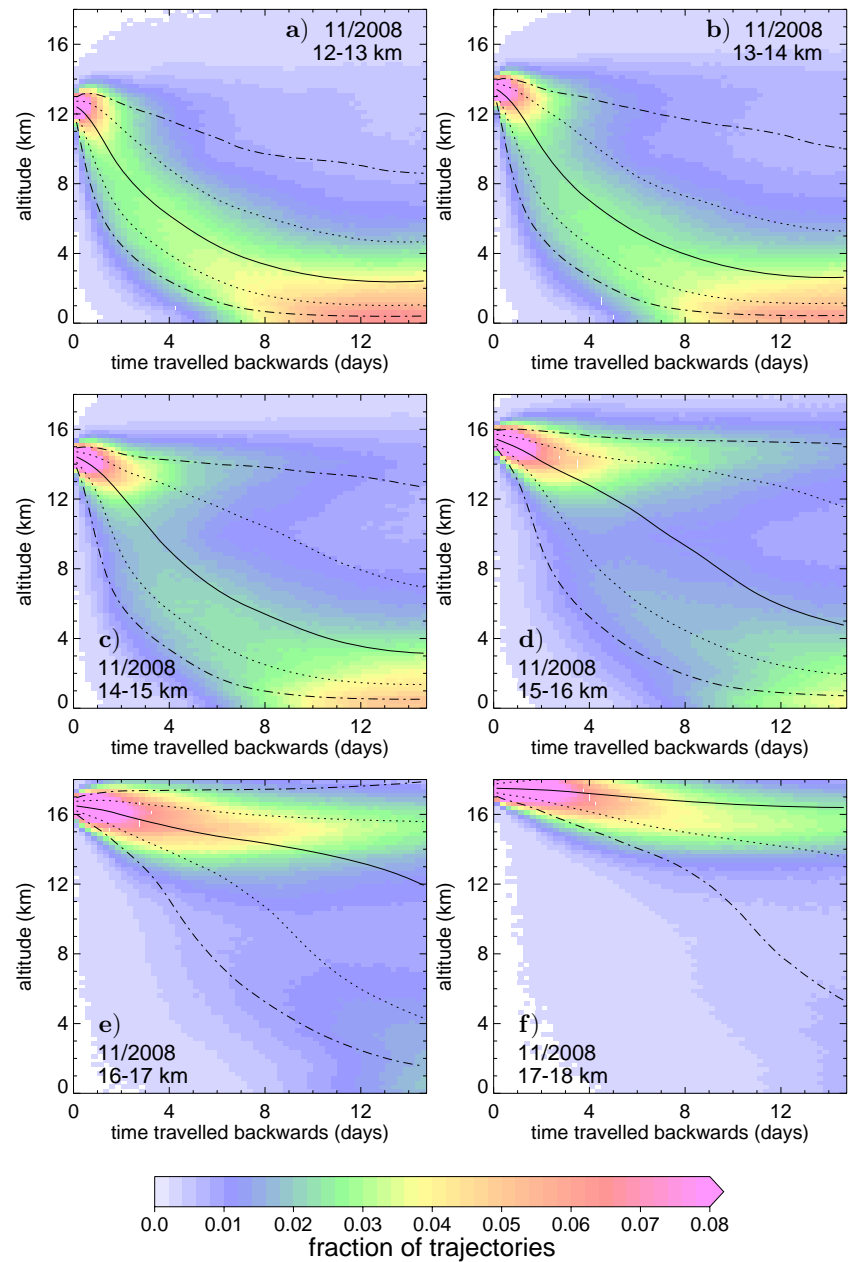

Fig. 2. Probability distributions of trajectory altitude as a function of time travelled backwards during November 2008. Plot (a) shows trajectories started between $12-13 \mathrm{~km}$, and (b-f) are for successive $1 \mathrm{~km}$ increases in starting altitude. Trajectories are grouped in to bins of $0.25 \mathrm{~km}$ (total 72) and 0.25 days (total 60). The median trajectory altitude is marked with a solid black line; 25th and 75th percentiles are marked with dotted lines; 10th and 90th percentiles are marked with dot-dash lines.

than in 2008 up to $\sim 13.5 \mathrm{~km}$, but larger above $\sim 13.5 \mathrm{~km}$; the trends are similar when $4 \mathrm{~km}$ is considered.

Further details of the differences between the years are shown in Fig. 4, which compares $1 \mathrm{~km}$ crossing locations for trajectories started between $12-13 \mathrm{~km}$ in each November. As in 2008, during the 2006 El Niño, the Western Pacific is the most likely location for trajectories to cross $1 \mathrm{~km}$. However, less than half as many trajectories reach $1 \mathrm{~km}$ in 2006 as do so in 2008 (see also Fig. 3). The pattern during the 2007 La Niña is slightly different. While the Western Pacific remains important, trajectories are also likely to cross $1 \mathrm{~km}$ in an arc stretching westwards to the island of Sumatra. The fraction of trajectories started between $12-13 \mathrm{~km}$ that cross

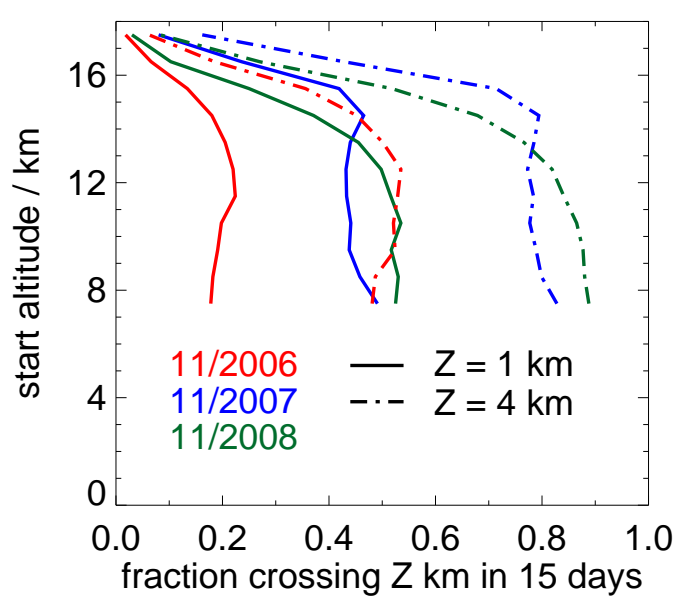

Fig. 3. For each of the three Novembers studied, the fraction of back trajectories starting in $1 \mathrm{~km}$ bins between $7-18 \mathrm{~km}$ that cross $1 \mathrm{~km}$ (solid lines) and $4 \mathrm{~km}$ (dot-dash lines) within 15 days.

$1 \mathrm{~km}$ during 2007 is approximately equal to the fraction in 2008 (again shown in Fig. 3).

Figure 5 considers trajectories started between $15-16 \mathrm{~km}$. In all three years the Western Pacific is the dominant boundary layer source to this altitude range in the TTL over Borneo. However, the fraction of trajectories that reach $1 \mathrm{~km}$ is quite different in each year, with more than 3 times as many doing so in 2007 than in 2006. Another metric for yearto-year variability is the time taken for $10 \%$ of trajectories started between $15-16 \mathrm{~km}$ to reach $1 \mathrm{~km}: \sim 13$ days in 2006 , $\sim 6$ days in 2007 and $\sim 9$ days in 2008. VSLS measurements made in the TTL, in a particular year, need to be interpreted with this type of variability in mind.

Interannual differences are also apparent in Fig. 6, which compares the $12-13 \mathrm{~km}$ and $15-16 \mathrm{~km}$ altitude versus time probability distributions for November 2008 (Fig. 2a and d) with the Novembers of 2006 and 2007. In the case of trajectories started between $12-13 \mathrm{~km}$, the $2006 \mathrm{El}$ Niño is again an outlying year, with the rate at which the trajectories ascend towards the TTL far slower than in the other years. At this starting altitude 2007 and 2008 are similar, though the population of trajectories that originate in the lower troposphere are more densely packed in the ENSO-neutral 2008 than in the La Niña of 2007. The behaviour of the trajectories started between $15-16 \mathrm{~km}$ is different in each of the years studied. In 2006, most of the trajectories travel at a fairly constant altitude towards the TTL above Borneo, while in 2007, most originate in the lower troposphere. And in 2008, as noted in Sect. 2.1, there is an approximately even split between these two distinct source altitudes.

\subsection{Variability of an idealised VSLS in the TTL}

We now consider how the results presented in Sects. 2.1 and 2.2 might be related to the abundance of a VSLS, such 
a)

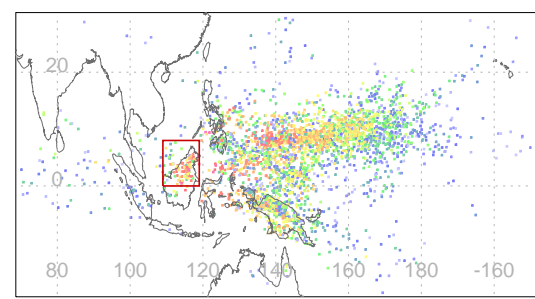

b)

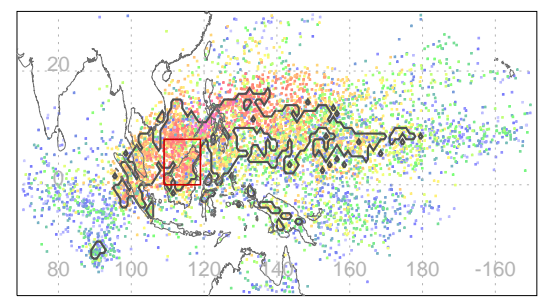

c)

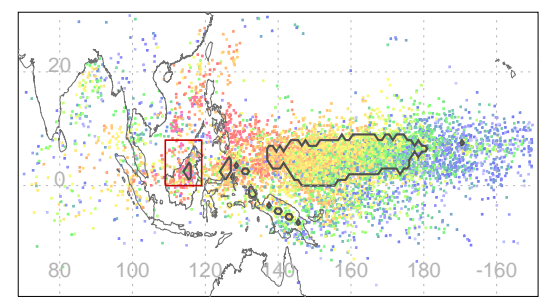

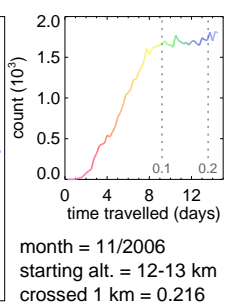
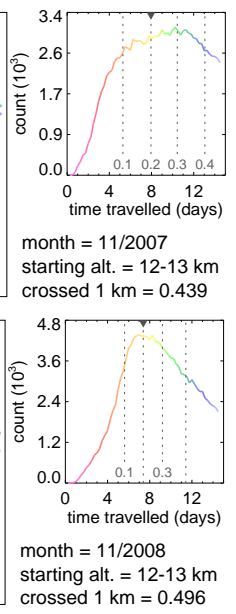

Fig. 4. As for Fig. 1 but focussing on trajectories started between 12-13 km for the Novembers of 2006, 2007 and 2008.

as $\mathrm{CHBr}_{3}$, in the TTL. The method we use to answer this question is simple; how sensitive our results might be to the assumptions we make is addressed later, in Sect. 4. Our calculations use an idealised tracer with an e-folding lifetime of 15 days (henceforth T15), which is comparable to that expected for $\mathrm{CHBr}_{3}$ in the tropics. Exponential loss is likely to be a reasonable approximation for a species such as $\mathrm{CHBr}_{3}$ that is lost primarily by photolysis.

The method first follows a trajectory, started in the TTL, backwards in time until it reaches $1 \mathrm{~km}$ above the surface; this altitude is used as a proxy for an encounter with a wellmixed boundary layer. The same trajectory is then followed forwards, from $1 \mathrm{~km}$ to its destination in the TTL, and the tracer, T15, is depleted exponentially along its path. We average over all trajectories of interest (e.g. those started from a particular altitude, or started at a certain time) and assume that those trajectories not reaching the boundary layer within 15 days contribute zero, and act to dilute the tracer concentration in the TTL. The term "T15 fraction" is used to describe the fraction of T15 that reaches the TTL relative to an initialisation of unity at $1 \mathrm{~km}$.

We wish to consider the variability in T15 fraction over the course of the months we have considered, and to do this have split each month in to 120 periods of $6 \mathrm{~h}$. Figure 7 shows, for TTL altitude ranges of $12-13 \mathrm{~km}$ and $15-16 \mathrm{~km}$, the temporal evolution of T15 fraction over each November considered, and summarises the temporal variability within each month. At each altitude range, and over each November,

a)
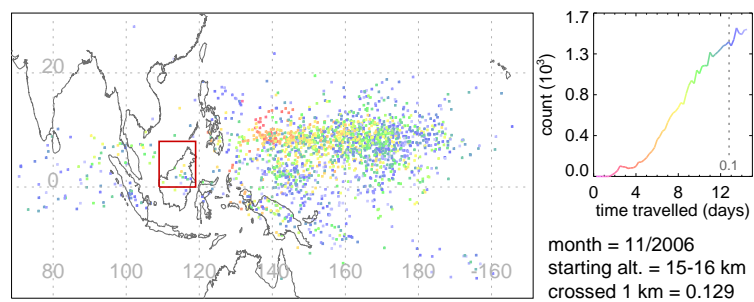

b)
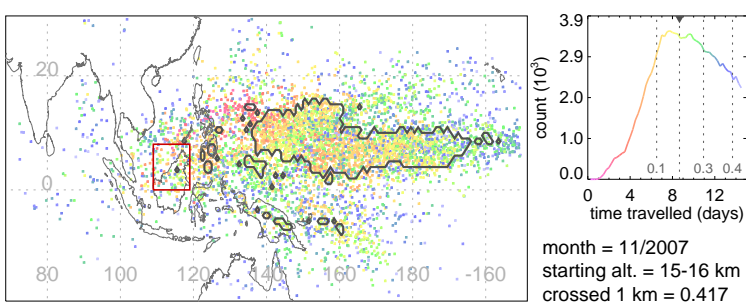

c)
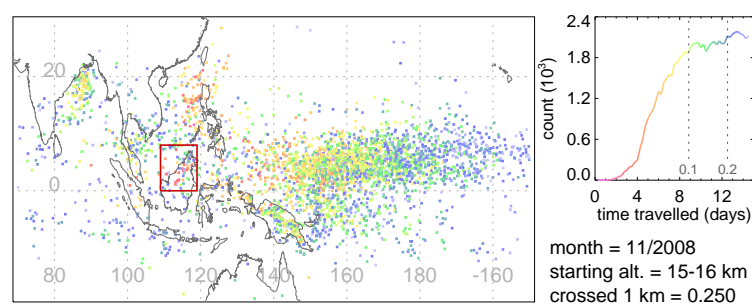

Fig. 5. As for Fig. 1 but focussing on trajectories started between $15-16 \mathrm{~km}$ for the Novembers of 2006, 2007 and 2008.

there is significant variability; the implication here is that sampling the TTL on two different days might lead to very different measured distributions. The same applies to measurements made at different altitudes. For example, Fig. 7 shows that statistically similar T15 fractions are calculated for 12-13 km during the Novembers of 2007 and 2008. But, the pattern is different at $15-16 \mathrm{~km}$, where the T15 fraction during the 2007 La Niña is, on average, almost twice that during November 2008.

\section{Existing aircraft measurements}

As we note in Sect. 2, to date there have been no measurements of VSLS in the TTL over Southeast Asia. However, some observations, made in other parts of the tropics, do exist. In this section, we describe data collected in the TTL over Central America, and then in Sect. 4 we present further trajectory calculations that can be compared directly with these measurements in an attempt to justify our methodology.

Two examples of aircraft campaigns that have measured VSLS in the TTL are the NASA campaigns CR-AVE and TC4, which were both based in Costa Rica, and sampled the TTL largely over the eastern Pacific adjacent to central America. CR-AVE took place during January and February 2006. Local TTL vertical transport rates have been inferred from CR-AVE measurements of $\mathrm{CO}_{2}$ and other species by Park et al. (2007), who also found evidence that convection 

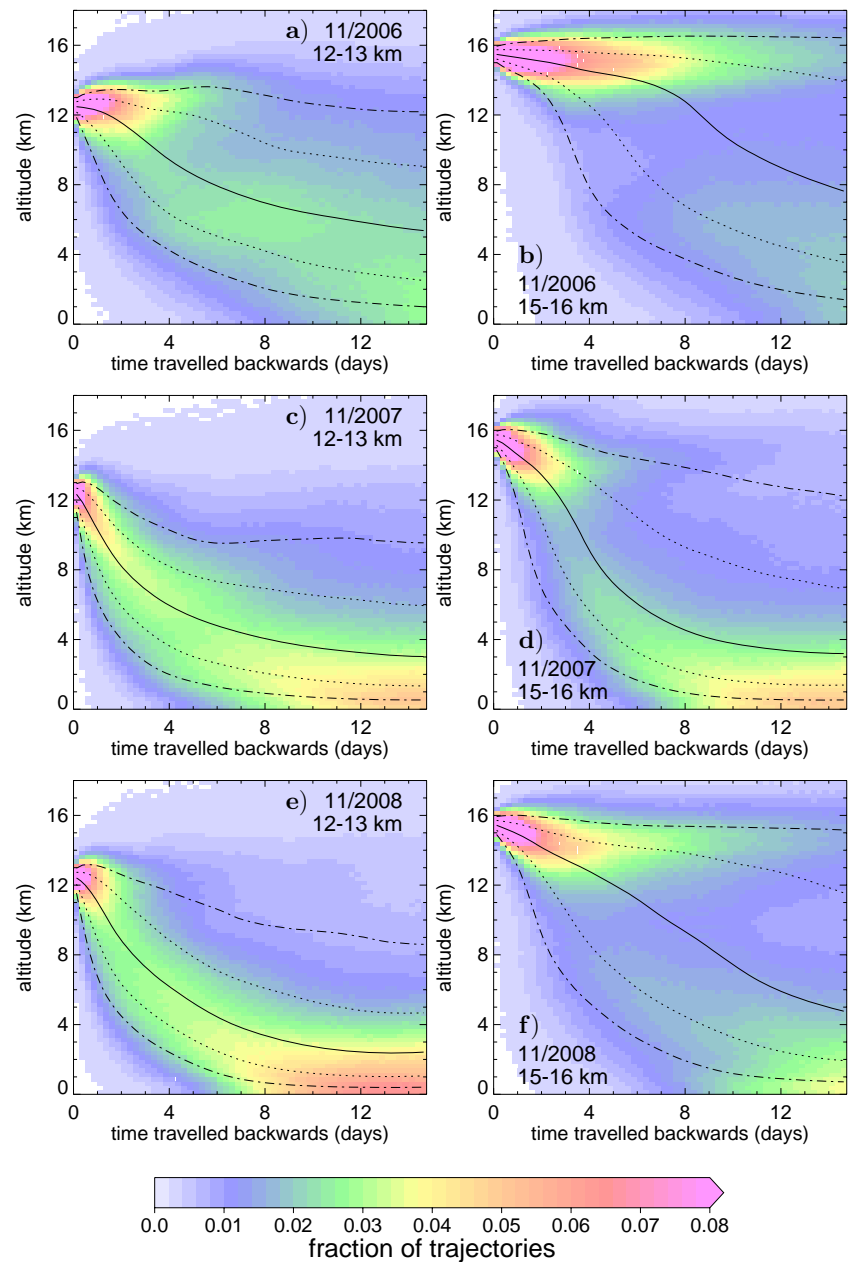

Fig. 6. Probability distributions of trajectory altitude as a function of time travelled backwards during November 2006 (a, b), 2007 (c, d) and 2008 (e, f). Plots (a), (c) and (e) show trajectories started between $12-13 \mathrm{~km}$, and plots (b), (d) and (f) show trajectories started between $15-16 \mathrm{~km}$. See additional information in Fig. 2.

as far away as the Western Pacific influenced the observed chemical composition. In the following analysis we have considered CR-AVE measurements made by whole air sampler (WAS) on the $10 \mathrm{WB}-57$ flights that collected more than 10 samples between $11-17.5 \mathrm{~km}$ within the tropics. The WAS comprised 50 1.5-l electropolished stainless steel canisters equipped with automated metal valves which were pressurised to 40 psi using a 4-stage bellows pump in flight (Flocke et al., 1999).

The TC4 campaign (Toon et al., 2010) occurred in July and August 2007 and featured 3 NASA aircraft. A summary of the aims of each days flights is provided by Toon et al. (2010) but a key point is that many TTL samples were collected in the vicinity of deep convection. Pfister et al. (2010) provide a meteorological overview of the campaign and note that the beginnings of a La Niña led to lower than average levels of deep convection. Again making use of $\mathrm{CO}_{2}$ measurements,

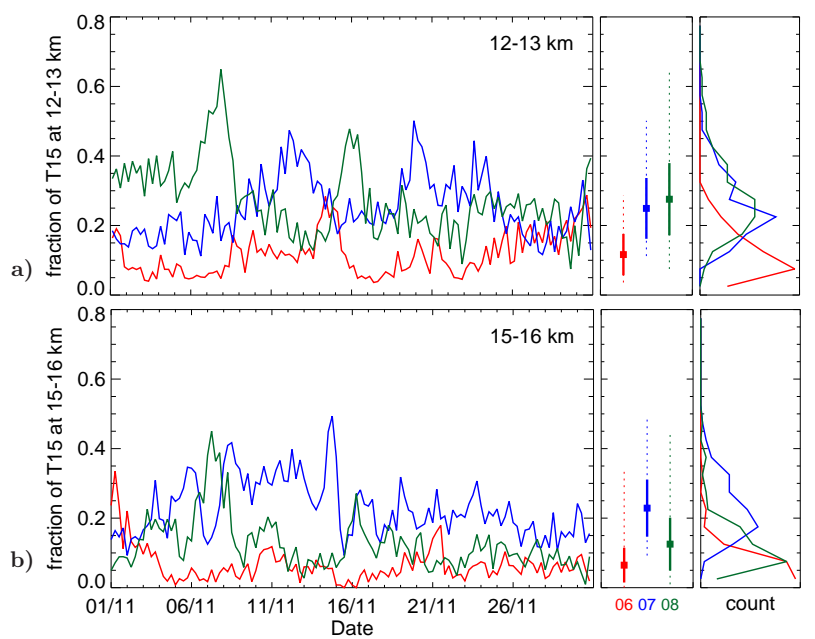

Fig. 7. Plot (a) shows a timeseries of the fraction of $\mathrm{T} 15$ (a $\mathrm{CHBr}_{3}$ like tracer) relative to an initialisation value at $1 \mathrm{~km}$ that reaches an altitude of $12-13 \mathrm{~km}$ above Borneo for the Novembers of 2006-2008. A statistical summary is provided by (1) the "box and whisker" plot to the right, with the monthly mean marked with a square, the bold lines denoting \pm 1 standard deviation, and the dotted line representing the range and (2) a probability distribution to the far right (bin size 0.05). Plot (b) provides the same information, but for an altitude of $15-16 \mathrm{~km}$.

Park et al. (2010) found that upward motion in the TTL was slower during TC4 than it had been during CR-AVE. In the following sections, we examine TTL data from the 3 tropical WB-57 flights.

We focus on observations of 3 VSLS with predominantly natural, oceanic sources: $\mathrm{CH}_{2} \mathrm{Br}_{2}, \mathrm{CHBr}_{3}$ and methyl iodide $\left(\mathrm{CH}_{3} \mathrm{I}\right)$. The 3 compounds have, under particular oxidative conditions, lifetimes of 123, 24 and 7 days respectively (Montzka and Reimann, 2011). These lifetimes are of course variable; for example, models suggest that $\mathrm{CHBr}_{3}$ has a shorter, $\sim 15$ day lifetime in the tropical troposphere and $\mathrm{CH}_{2} \mathrm{Br}_{2}$ a longer, 6-12 month lifetime in the TTL (e.g. Warwick et al., 2006; Liang et al., 2010; Hossaini et al., 2010; Park et al., 2010). Nevertheless, this range of lifetimes means that these compounds are expected to have varying stratospheric impacts (see Gettelman et al., 2009; Aschmann et al., 2009).

Data collected during both CR-AVE and TC4 are presented in Fig. 8. There are clear differences between the campaigns. During CR-AVE the rate at which the abundance of each species decreases with altitude is relatively slow (see Park et al., 2010), and there is significant variability throughout the TTL. For example, at $\sim 17 \mathrm{~km} \mathrm{CH}_{2} \mathrm{Br}_{2}$ ranges over an order of magnitude and $\mathrm{CHBr}_{3}$ between $\sim 0-0.5 \mathrm{ppt}$. In contrast, during TC4 the negative gradients are steeper, there is less variability in the observations within each altitude bin, and very low concentrations of $\mathrm{CHBr}_{3}$ and $\mathrm{CH}_{3} \mathrm{I}$ were found above $\sim 15 \mathrm{~km}$. 

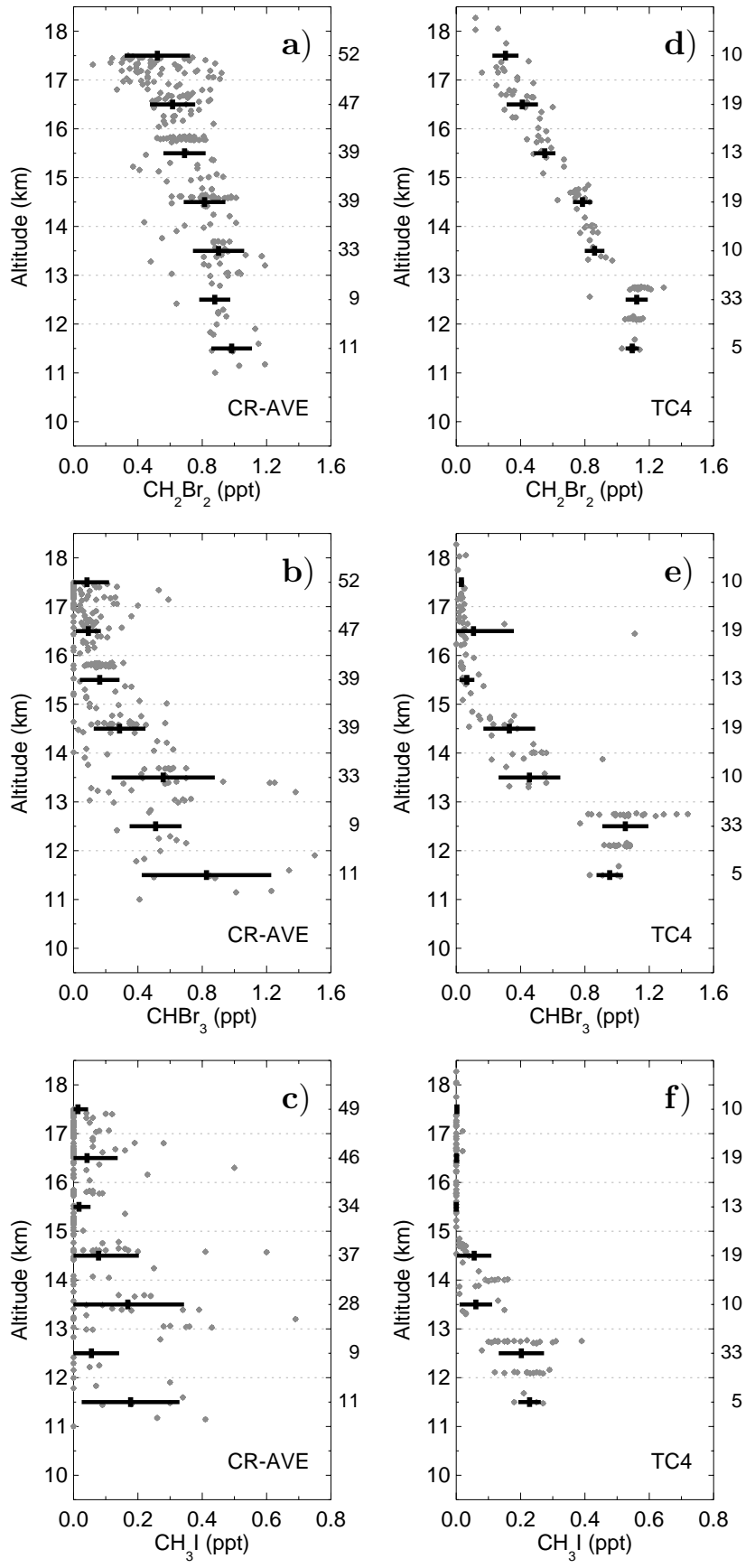

Fig. 8. Selected halocarbons measured by whole air sampler aboard the WB-57 during CR-AVE (a-c) and TC4 (d-f). Plots (a) and (d) show $\mathrm{CH}_{2} \mathrm{Br}_{2}$, (b) and (e) show $\mathrm{CHBr}_{3}$, and (c) and (f) show $\mathrm{CH}_{3} \mathrm{I}$; so lifetimes decrease from top to bottom. The number of measurements in successive $1 \mathrm{~km}$ altitude bins is noted to the right of each plot. The solid black lines show the mean \pm 1 standard deviation in each bin.

In the following section we perform further trajectory calculations that aim to test the methodology with which, in Sect. 2, we reached conclusions concerning the time and location of transport pathways to the TTL over Borneo. Can our method qualitatively reproduce the behaviour observed during CR-AVE and TC4?

\section{Trajectory study related to aircraft measurements}

In our second set of calculations we release batches of 10000 15-day back trajectories from the time and location of each individual measurement in Fig. 8 (230 measurements in CRAVE, 112 in TC4, which gives a total of 3.42 million trajectories). As in Sect. 2.3, we calculate the fraction of an exponentially depleted tracer initialised at $1 \mathrm{~km}$ that remains at its destination in the TTL. Here, we use two lifetimes: 15 days, which can be compared to $\mathrm{CHBr}_{3}$ observations, and 5 days, for comparison with $\mathrm{CH}_{3} \mathrm{I}$. Accordingly, we refer to the tracer remaining in the TTL as "T15 fraction" or "T5 fraction".

Figure 9 shows, for both campaigns, the tracer fraction for batches of trajectories released for each of the samples. If initially only the shapes of the tracer fraction profiles are considered, then the observed differences between the 2 campaigns (Fig. 8) are reproduced: (1) the negative gradient is shallower during CR-AVE than during TC4; (2) tracer fractions within each altitude bin during CR-AVE are more variable than those during TC4; (3) there is a clear discontinuity in the TC4 tracer fractions at $\sim 15 \mathrm{~km}$, above which nearzero tracer fractions are calculated. Tracer fractions are, in general, underestimated above $\sim 15 \mathrm{~km}$ in CR-AVE, and between $\sim 11-13 \mathrm{~km}$ in TC4. Another way to look at these data is presented in Fig. 10, where for both campaigns, the $\mathrm{CHBr}_{3}$ observations are compared directly with calculated T15 fractions. Agreement between model and observation is closest where data lie near the grey lines. Again, it is clear that our trajectory calculations lead to too small a T15 fraction in the upper TTL during CR-AVE. We suggest one possible reason for this in Sect. 5.

Figures 8,9 and 10 show that the trajectory calculations, as campaign means, are in many respects consistent with the observations. However, they do not provide any information about the ability of the trajectories to reproduce the observed day-to-day variability. In Fig. 11 we compare $\mathrm{CHBr}_{3}$ observations from individual flights with the calculated T15 fraction. We have selected 3 of the 10 CR-AVE flights for this analysis; the 19 and 21 January, and the 7 February. On each of these days measurements were made through most of the depth of the TTL. In addition, relatively low concentrations of $\mathrm{CH}_{3} \mathrm{I}$ were observed on these days, so we expect that the measured air masses had not been heavily influenced by oceanic convection in the past few days. On each of these days we find that the shape of the calculated T15 fraction profile compares well with the $\mathrm{CHBr}_{3}$ observations. On 19 January the latitudinal difference (see the caption of Fig. 11) is clearly reproduced qualitatively in the calculated T15 fraction. On 21 January relatively low $\mathrm{CHBr}_{3}$ concentrations $(<0.25 \mathrm{ppt})$ were found throughout the TTL. Again, the 

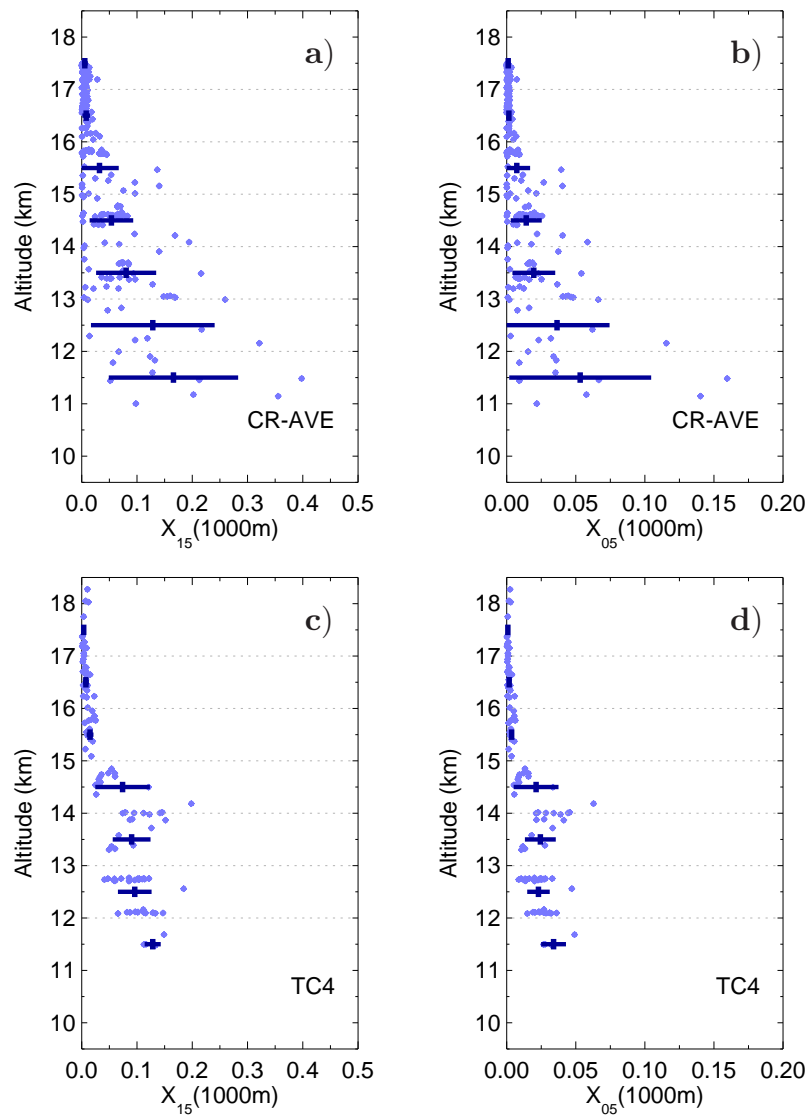

Fig. 9. TTL tracer fraction (i.e. assuming a boundary layer concentration of 1) calculated from NAME back trajectories corresponding to the measurements presented in Fig. 8 for CR-AVE (a, b) and TC4 (c, d). The tracer is initialised at $1 \mathrm{~km}$ a.g.l. In (a) and (c) the tracer has an e-folding lifetime of 15 days, in (b) and (d) an e-folding lifetime of 5 days. The solid dark blue lines show the mean \pm 1 standard deviation in each $1 \mathrm{~km}$ altitude bin. Note that the horizontal scales are not all the same.

calculated T15 fractions are consistent with the observations. And finally, on 7 February, $\mathrm{CHBr}_{3}$ was observed to decrease with altitude at a fairly uniform rate. Once more, the T15 fraction profile is similar.

To scale both the T5 and T15 fractions to the $\mathrm{CH}_{3} \mathrm{I}$ and $\mathrm{CHBr}_{3}$ measurements requires a factor of, in both cases, $\sim 4$ (see the grey lines in Fig. 10 for T15). The calculations are therefore consistent with boundary layer concentrations of 4 ppt of both species. Such mixing ratios have generally been observed only where sources are nearby, and are double what might be regarded as "background" levels (e.g. $\mathrm{CHBr}_{3}$ measurements reported by Yokouchi et al., 2005; Carpenter et al., 2005; Zhou et al., 2008; Pyle et al., 2011).

Given the simplicity of our approach, we consider the agreement to be reasonably good. Nevertheless, we now consider three possible sources of uncertainty (trajectory length, tracer lifetime and altitude of initialisation) in order to get an

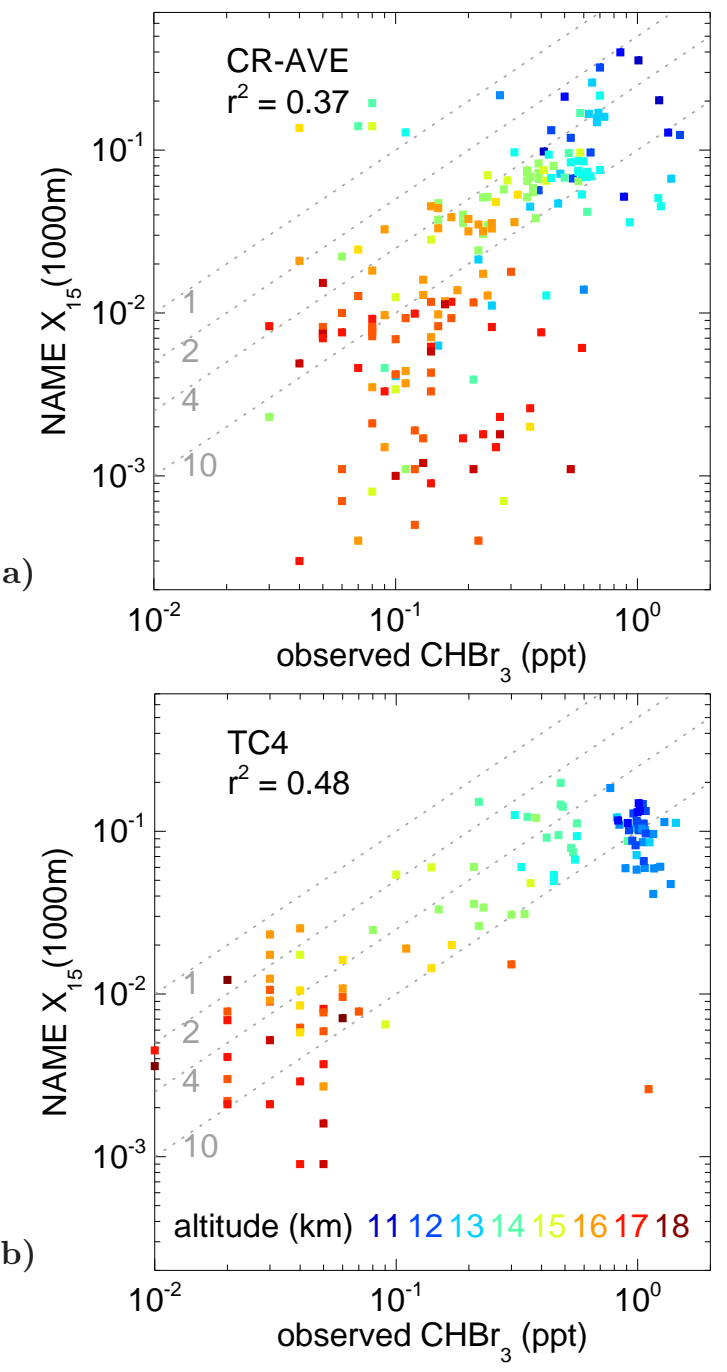

Fig. 10. The correlation between observed $\mathrm{CHBr}_{3}$ and modelled T15 during CR-AVE (plot (a), data from Fig. 8b and Fig. 9a) and TC4 (plot (b), data from Fig. 8e and Fig. 9c). The dots are coloured by altitude - see the legend at the bottom of plot (b). The grey lines indicate where there is a linear relationship between observation and model, and the scaling factor required to match model to observation is noted at the left end of each line. Note that $\mathrm{CHBr}_{3}$ was not detected in 47 (2) out of 230 (112) samples collected during CRAVE (TC4); these data are not presented in plot (a) or (b), though they are included in the correlation coefficient calculations.

idea of their possible importance. We recognise that this is an incomplete analysis, not least because of the problems in assessing the quality of the wind fields.

If we extend a subset of the trajectory calculation to 30 days then, typically, less than $\sim 10 \%(\sim 3 \%)$ of T15 is unaccounted for in the lower (upper) TTL by considering only the first 15 days of travel. So, while a relatively small deficit, this simplification clearly contributes to the model underestimation of the $\mathrm{CHBr}_{3}$ observations. This is particularly true of higher altitudes, where VSLS tend to be less abundant, 

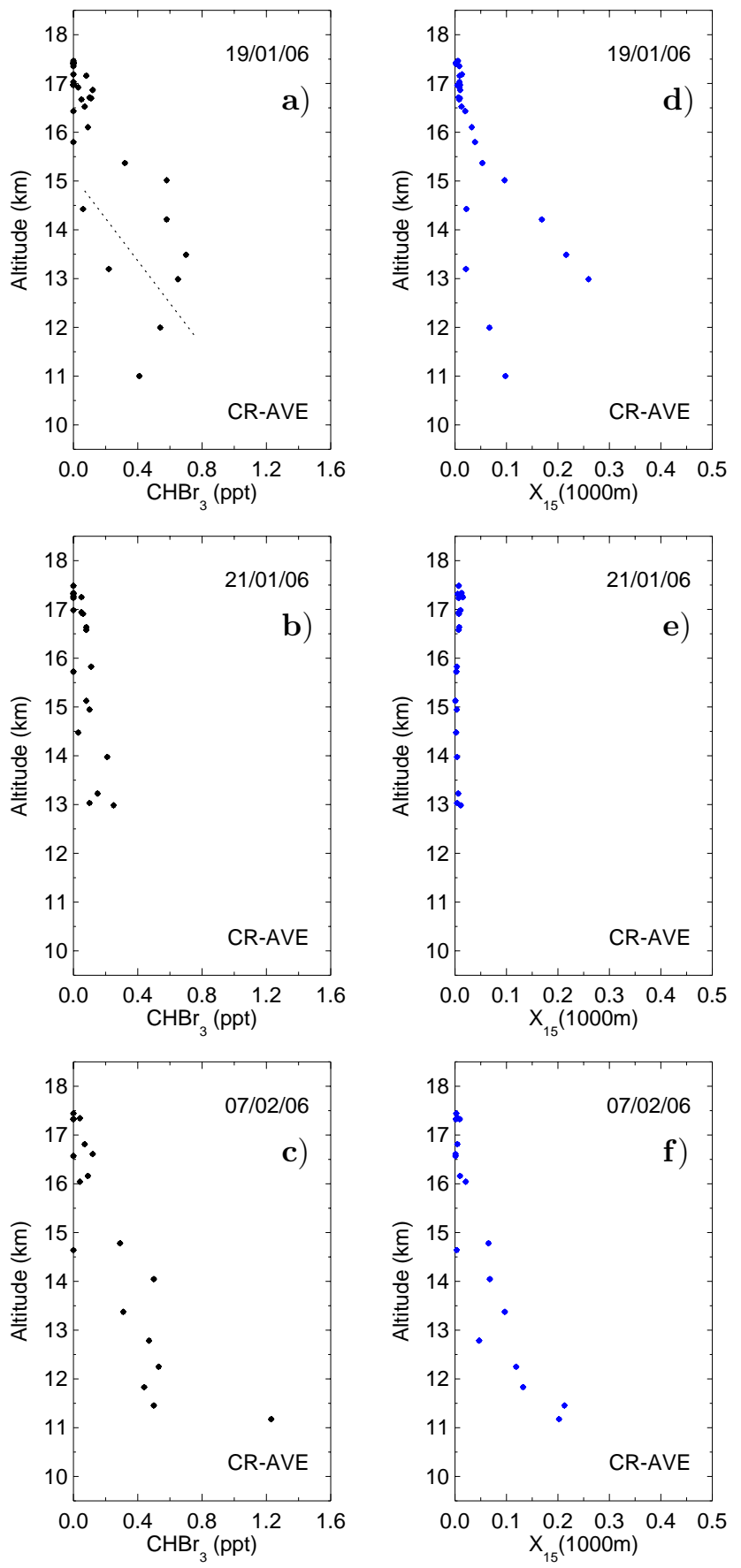

Fig. 11. A comparison between $\mathrm{CHBr}_{3}$ observed on selected days of CR-AVE $(\mathbf{a}-\mathbf{c})$ and NAME calculated profiles of a tracer with 15 day e-folding lifetime for the same sample locations and times (d-f). The dashed line in (a) separates observations collected on two different descents through the TTL; lower mixing ratios were found at $\sim 10^{\circ} \mathrm{N}$, and higher mixing ratios found near the equator.

and a $\sim 3 \%$ increase in T15 would somewhat improve the linear fits presented in Fig. 10. There is a negligible $(<1 \%)$ increase in $\mathrm{T} 5$ fraction when calculated with 30 day, rather than 15 day back trajectories. The assumption of a 15 day lifetime for $\mathrm{CHBr}_{3}$ is likely to be a valid approximation for the atmosphere in which the trajectories travel (i.e. the tropical troposphere). As noted in Sect. 3, there is evidence for a marginally longer $\mathrm{CHBr}_{3}$ lifetime in the TTL; this is another possible reason our calculations require high boundary layer concentrations to be consistent with the observations. If we adjust the initialisation altitude (recall this is a proxy for the assumed depth of a well-mixed boundary layer) to $1.5 \mathrm{~km}$ $(0.5 \mathrm{~km})$ then over the 15 day travel time $\sim 15 \%$ more (fewer) trajectories cross $1 \mathrm{~km}$; these differences are relatively minor in our simplistic method.

We have also examined where the CR-AVE and TC4 back trajectories reach $1 \mathrm{~km}$ above the surface. Through their analysis of CR-AVE measurements, Park et al. (2007) identified air masses likely to have originated locally, likely to have come from the Amazon, and likely to have travelled from the tropical Pacific. In Fig. 12a and b, which are analogous to Figs. 1, 4 and 5, we show that our trajectories are broadly consistent with Park et al. (2007). A small number of trajectories starting between $12-13 \mathrm{~km}$ reached the boundary layer locally within a few days. The tropical Atlantic is also an important source, and a large fraction of our trajectories have travelled for 8-10 days from the tropical Western and Central Pacific boundary layer. However, few of our trajectories reach the boundary layer over the Amazon. Overall, 25\% of CR-AVE trajectories starting between 12-13 km crossed $1 \mathrm{~km}$ within 15 days. Almost no trajectories started between $15-16 \mathrm{~km}$ reached the boundary layer locally, or over the Atlantic. Instead, the South Pacific convergence zone appears to be the most important boundary layer source for air masses ending up in this altitude range, consistent with large-scale convection in this region.

Unlike CR-AVE, few TC4 trajectories reach the boundary layer over the Pacific, which is consistent with the strong prevailing easterly winds in TTL described by Pfister et al. (2010). Instead, most trajectories that reached $1 \mathrm{~km}$ did so over the Amazon, over the tropical Atlantic, and over Western Africa. There are some similarities between these results and the trajectory calculations of Pfister et al. (2010), though the methods used are quite different.

Fewer trajectories reach $1 \mathrm{~km}$ within 15 days during CRAVE and TC4 than do so from the TTL above Borneo. At 12$13 \mathrm{~km}$, the Central America fractions are comparable with the 2006 Borneo fractions (during an El Niño), but only half as large as the 2007 and 2008 Borneo fractions (respectively, La Niña and ENSO-neutral NH winters). At $15-16 \mathrm{~km}$, the differences are more marked. For example, $\sim 3 \%$ of the TC 4 trajectories reached $1 \mathrm{~km}$, and 4 months later, in November 2007, $\sim 42 \%$ of trajectories started over Borneo did so.

\section{Discussion and conclusions}

The NAME trajectory model has been used to investigate the statistical behaviour of air masses reaching the TTL. Our aim 

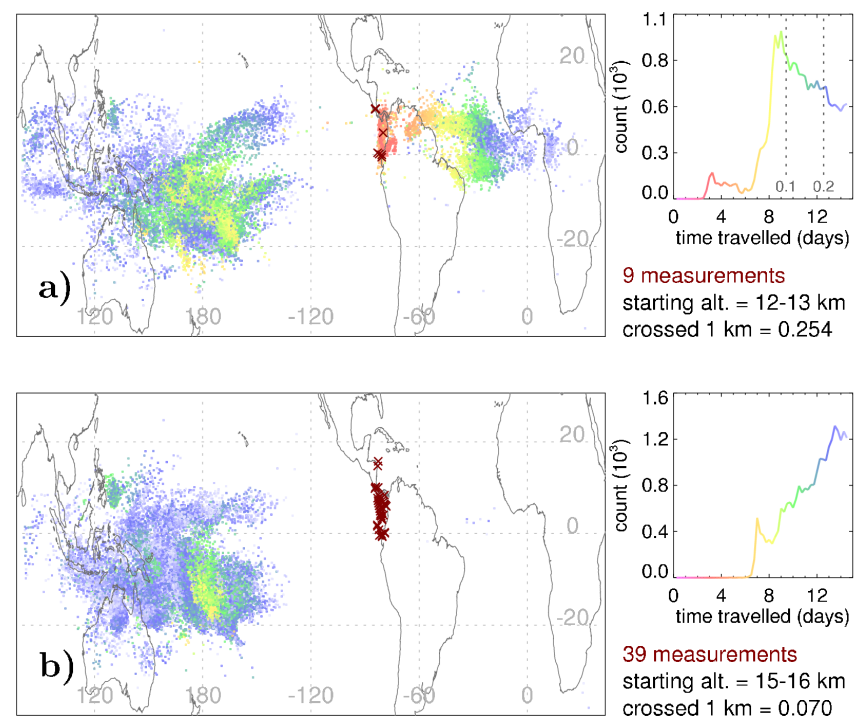
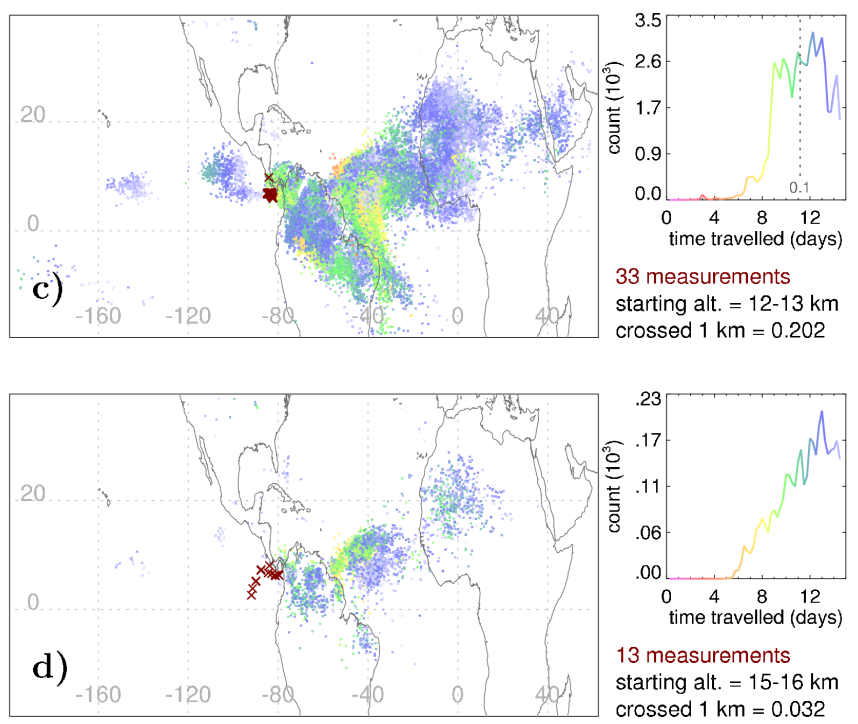

Fig. 12. On the left of each plot, maps of trajectory $1 \mathrm{~km}$ crossing locations during CR-AVE (a, b) and TC4 (c, d). 10000 back trajectories start at each sample location (dark red crosses) in the following altitude bands: in (a) and (c) trajectories start between 12-13 km, in (b) and (d) between 15-16 km. Refer to Fig. 1 for additional information.

was to assist the planning of aircraft campaigns focussed on improving our knowledge of transport into and through the TTL. We have examined the conditions which might prevail for a future campaign and looked at 2 previous campaigns in order to test the validity of the approach. In the longer-term this approach should prove valuable in planning flights for long duration aircraft such as the unmanned Global Hawk where many more measurements can be made.

VSLS measurements have been made from high-flying aircraft during CR-AVE (January and February 2006) and TC4 (July and August 2007). Batches of back trajectories were run from a selection of these flights. The features of the observed vertical profiles of $\mathrm{CHBr}_{3}$ and $\mathrm{CH}_{3} \mathrm{I}$ are broadly similar to those of hypothetical tracers with 15 day and 5 day lifetimes. The drop-off with altitude was captured, as were differences between individual flights. As our method assumes a uniform VSLS concentration in the boundary layer, our results therefore suggest that the measurements examined here were not affected by highly variable "hot spot" emissions. Consistent with previous work (Park et al., 2010), weaker uplift was found during TC4 than during CR-AVE. Nevertheless, our model calculations clearly underestimate the flux of VSLS to the upper TTL during CR-AVE; our interpretation is that NAME, and the underlying meteorological analyses, accurately capture the main body of convective outflow between 11-14 km, but do not represent the stronger convective systems that reach higher altitudes. In terms of locations where air last left the boundary layer, there were marked differences between the two campaigns. During CR-AVE the West Pacific was the main region of supply, although the tropical Atlantic was also a contributor at lower altitudes (12-13 km). During TC4, however, boundary layer air was predominantly sourced from the tropical Atlantic, South America and West Africa. These findings are broadly consistent with the dominant regions of convection in the two seasons.

The same approach has been used to aid campaign planning for the SHIVA measurement phase during November 2011. We used November 2008 (neutral) as our base case to investigate the origins of air in the TTL over Borneo. Our 2008 trajectories show that this particular part of the TTL consists of two regimes. Air in the lower TTL typically comes from the lower troposphere (below $4 \mathrm{~km}$ ) with rapid upward transport occurring over several days prior to arriving. Though of course we have used three-dimensional wind fields without an explicit representation of convection, this result appears to support the concept that upward transport from the boundary layer occurs in more than one step, with low-level convection feeding rapid transport to the lower TTL from $\sim 4 \mathrm{~km}$ (Hosking et al., 2010). Air in the upper TTL has largely travelled quasi-horizontally through the TTL over the past 15 days. In 2008, the transition between these two regimes occurs at $\sim 15-16 \mathrm{~km}$. Most of the trajectories that reached the boundary layer travelled from the Western Pacific, $\sim 20-40^{\circ}$ E of Borneo, suggesting that measurements of VSLS in the TTL over Borneo might be strongly influenced by the lower tropospheric concentrations in this region. We note that our calculations for the CR-AVE campaign also highlight the Western Pacific region as the dominant boundary layer source to $15-16 \mathrm{~km}$ during $\mathrm{NH}$ winter; further nearsurface measurements of VSLS in the Western Pacific might therefore be particularly valuable.

Similar calculations were made for moderate El Niño (2006) and La Niña (2007) conditions. Large differences 
were found. During the El Niño, there was much less upward transport to this part of the TTL, and the influence of the boundary layer in the Maritime Continent is much smaller. In La Niña conditions, the amount of upward transport to $12-13 \mathrm{~km}$ is similar to the neutral case, though there was a greater influence of the boundary layer close to Borneo. Upward transport to higher altitudes in the TTL was stronger during the La Niña than during neutral conditions. It is worth emphasising that we have focussed on a small, but probably important, part of the TTL, and the influence of ENSO will be different in other parts of the tropics.

More chemical measurements (of short- and long-lived species) will be required to understand the transition between $12 \mathrm{~km}$ and the stratosphere. High altitude observations, such as those from the long duration Global Hawk, could play a valuable role in this. In order to maximise the information gathered from these flights, the approach presented here can be developed further to guide the aircraft into regions of specific interest (e.g. where the influence of the boundary layer is weak, intermediate or strong). In conjunction with highresolution mesoscale models capable of simulating convection, it should also be possible to investigate the locations where local convection is important. This is challenging because the variability is high (see Sect. 2.3), and statistical approaches based upon large numbers of measurements are likely to be needed to extract the required information.

Acknowledgements. This work was supported by the European Commission through the SHIVA project (FP7-ENV-2007-1226224). Matt Ashfold thanks NERC for a research studentship. Neil Harris is supported by a NERC Advanced Research Fellowship. We also thank Glenn Carver for help with running NAME.

Edited by: P. Haynes

\section{References}

Aschmann, J., Sinnhuber, B.-M., Atlas, E. L., and Schauffler, S. M.: Modeling the transport of very short-lived substances into the tropical upper troposphere and lower stratosphere, Atmos. Chem. Phys., 9, 9237-9247, doi:10.5194/acp-9-9237-2009, 2009.

Butler, J. H., King, D. B., Lobert, J. M., Montzka, S. A., YvonLewis, S. A., Hall, B. D., Warwick, N. J., Mondeel, D. J., Aydin, M., and Elkins, J. W.: Oceanic distributions and emissions of short-lived halocarbons, Global Biogeochem. Cy., 21, GB1023, doi:10.1029/2006GB002732, 2007.

Carpenter, L. J., Wevill, D. J., O’Doherty, S., Spain, G., and Simmonds, P. G.: Atmospheric bromoform at Mace Head, Ireland: seasonality and evidence for a peatland source, Atmos. Chem. Phys., 5, 2927-2934, doi:10.5194/acp-5-2927-2005, 2005.

Davies, T., Cullen, M. J. P., Malcolm, A. J., Mawson, M. H., Staniforth, A., White, A. A., and Wood, N.: A new dynamical core for the Met Office's global and regional modelling of the atmosphere, Q. J. Roy. Meteorol. Soc., 131, 1759-1782, 2005.

Dorf, M., Butler, J. H., Butz, A., Camy-Peyret, C., Chipperfield, M. P., Kritten, L., Montzka, S. A., Simmes, B., Weidner, F., and
Pfeilsticker, K.: Long-term observations of stratospheric bromine reveal slow down in growth, Geophys. Res. Lett., 33, L24803, doi:10.1029/2006GL027714, 2006.

FAO Fisheries and Aquaculture Department: The State of World Fisheries and Aquaculture 2010, Tech. rep., Food and Agriculture Organization of the United Nations, Rome, 2010.

Flocke, F., Herman, R. L., Salawitch, R. J., Atlas, E., Webster, C. R., Schauffler, S. M., Lueb, R. A., May, R. D., Moyer, E. J., Rosenlof, K. H., Scott, D. C., Blake, D. R., and Bui, T. P.: An examination of chemistry and transport processes in the tropical lower stratosphere using observations of long-lived and shortlived compounds obtained during STRAT and POLARIS, J. Geophys. Res., 104, 26625-26642, doi:10.1029/1999JD900504, 1999.

Fueglistaler, S., Wernli, H., and Peter, T.: Tropical troposphereto-stratosphere transport inferred from trajectory calculations, J. Geophys. Res.-Atmos., 109, D03108, doi:10.1029/2003JD004069, 2004.

Fueglistaler, S., Dessler, A. E., Dunkerton, T. J., Folkins, I., Fu, Q., and Mote, P. W.: Tropical Tropopause Layer, Rev. Geophys., 47, RG1004, doi:10.1029/2008RG000267, 2009.

Gettelman, A. and Forster, P. D. F.: A Climatology of the Tropical Tropopause Layer, Journal of the Meteorological Society of Japan, 80, 911-924, 2002.

Gettelman, A., Lauritzen, P. H., Park, M., and Kay, J. E.: Processes regulating short-lived species in the tropical tropopause layer, J. Geophys. Res.-Atmos., 114, D13303, doi:10.1029/2009JD011785, 2009.

Gostlow, B., Robinson, A. D., Harris, N. R. P., O’Brien, L. M., Oram, D. E., Mills, G. P., Newton, H. M., Yong, S. E., and A Pyle, J.: $\mu$ Dirac: an autonomous instrument for halocarbon measurements, Atmos. Meas. Tech., 3, 507-521, doi:10.5194/amt-3507-2010, 2010.

Heyes, W. J., Vaughan, G., Allen, G., Volz-Thomas, A., Pätz, H.W., and Busen, R.: Composition of the TTL over Darwin: local mixing or long-range transport?, Atmos. Chem. Phys., 9, 77257736, doi:10.5194/acp-9-7725-2009, 2009.

Hosking, J. S., Russo, M. R., Braesicke, P., and Pyle, J. A.: Modelling deep convection and its impacts on the tropical tropopause layer, Atmos. Chem. Phys., 10, 11175-11188, doi:10.5194/acp10-11175-2010, 2010.

Hossaini, R., Chipperfield, M. P., Monge-Sanz, B. M., Richards, N. A. D., Atlas, E., and Blake, D. R.: Bromoform and dibromomethane in the tropics: a 3-D model study of chemistry and transport, Atmos. Chem. Phys., 10, 719-735, doi:10.5194/acp10-719-2010, 2010.

Hoyle, C. R., Marécal, V., Russo, M. R., Allen, G., Arteta, J., Chemel, C., Chipperfield, M. P., D'Amato, F., Dessens, O., Feng, W., Hamilton, J. F., Harris, N. R. P., Hosking, J. S., Lewis, A. C., Morgenstern, O., Peter, T., Pyle, J. A., Reddmann, T., Richards, N. A. D., Telford, P. J., Tian, W., Viciani, S., Volz-Thomas, A., Wild, O., Yang, X., and Zeng, G.: Representation of tropical deep convection in atmospheric models - Part 2: Tracer transport, Atmos. Chem. Phys., 11, 8103-8131, doi:10.5194/acp-118103-2011, 2011.

Jones, A., Thomson, D., Hort, M., and Devenish, B.: The U.K. Met Office's Next-Generation Atmospheric Dispersion Model, NAME III, in: Air Pollution Modeling and Its Application XVII, edited by: Borrego, C. and Norman, A.-L., 580-589, Springer 
US, doi:10.1007/978-0-387-68854-1_62, 2007.

Krüger, K., Tegtmeier, S., and Rex, M.: Long-term climatology of air mass transport through the Tropical Tropopause Layer (TTL) during NH winter, Atmos. Chem. Phys., 8, 813-823, doi:10.5194/acp-8-813-2008, 2008.

Krüger, K., Tegtmeier, S., and Rex, M.: Variability of residence time in the Tropical Tropopause Layer during Northern Hemisphere winter, Atmos. Chem. Phys., 9, 6717-6725, doi:10.5194/acp-96717-2009, 2009.

Laube, J. C., Engel, A., Bönisch, H., Möbius, T., Worton, D. R., Sturges, W. T., Grunow, K., and Schmidt, U.: Contribution of very short-lived organic substances to stratospheric chlorine and bromine in the tropics - a case study, Atmos. Chem. Phys., 8, 7325-7334, doi:10.5194/acp-8-7325-2008, 2008.

Lawrence, M. G. and Rasch, P. J.: Tracer Transport in Deep Convective Updrafts: Plume Ensemble versus Bulk Formulations, J. Atmos. Sci., 62, 2880-2894, doi:10.1175/JAS3505.1, 2005.

Levine, J. G., Braesicke, P., Harris, N. R. P., Savage, N. H., and Pyle, J. A.: Pathways and timescales for troposphere-to-stratosphere transport via the tropical tropopause layer and their relevance for very short lived substances, J. Geophys. Res.-Atmos., 112, D04308, doi:10.1029/2005JD006940, 2007.

Levine, J. G., Braesicke, P., Harris, N. R. P., and Pyle, J. A.: Seasonal and inter-annual variations in troposphere-to-stratosphere transport from the tropical tropopause layer, Atmos. Chem. Phys., 8, 3689-3703, doi:10.5194/acp-8-3689-2008, 2008.

Liang, Q., Stolarski, R. S., Kawa, S. R., Nielsen, J. E., Douglass, A. R., Rodriguez, J. M., Blake, D. R., Atlas, E. L., and Ott, L. E.: Finding the missing stratospheric Bry: a global modeling study of $\mathrm{CHBr}_{3}$ and $\mathrm{CH}_{2} \mathrm{Br}_{2}$, Atmos. Chem. Phys., 10, 2269-2286, doi:10.5194/acp-10-2269-2010, 2010.

Mata, T. M., Martins, A. A., and Caetano, N. S.: Microalgae for biodiesel production and other applications: A review, Renewable and Sustainable Energy Reviews, 14, 217-232, doi:10.1016/j.rser.2009.07.020, 2010.

Montzka, S. A. and Reimann, S.: Ozone-Depleting Substances (ODSs) and Related Chemicals, vol. Scientific Assessment of Ozone Depletion: 2010, Global Ozone Research and Monitoring Project - Report No. 52, chap. 1, World Meteorological Organization (WMO), Geneva, 2011.

Morrison, N. L. and Webster, H. N.: An Assessment of Turbulence Profiles in Rural and Urban Environments Using Local Measurements and Numerical Weather Prediction Results, Bound.Lay. Meteorol., 115, 223-239, doi:10.1007/s10546-004-4422-8, 2005.

O’Brien, L. M., Harris, N. R. P., Robinson, A. D., Gostlow, B., Warwick, N., Yang, X., and Pyle, J. A.: Bromocarbons in the tropical marine boundary layer at the Cape Verde Observatory - measurements and modelling, Atmos. Chem. Phys., 9, 9083-9099, doi:10.5194/acp-9-9083-2009, 2009.

Park, S., Jiménez, R., Daube, B. C., Pfister, L., Conway, T. J., Gottlieb, E. W., Chow, V. Y., Curran, D. J., Matross, D. M., Bright, A., Atlas, E. L., Bui, T. P., Gao, R.-S., Twohy, C. H., and Wofsy, S. C.: The $\mathrm{CO}_{2}$ tracer clock for the Tropical Tropopause Layer, Atmos. Chem. Phys., 7, 3989-4000, doi:10.5194/acp-7-39892007, 2007.

Park, S., Atlas, E. L., Jiménez, R., Daube, B. C., Gottlieb, E. W., Nan, J., Jones, D. B. A., Pfister, L., Conway, T. J., Bui, T. P., Gao, R.-S., and Wofsy, S. C.: Vertical transport rates and con- centrations of $\mathrm{OH}$ and $\mathrm{Cl}$ radicals in the Tropical Tropopause Layer from observations of $\mathrm{CO}_{2}$ and halocarbons: implications for distributions of long- and short-lived chemical species, Atmos. Chem. Phys., 10, 6669-6684, doi:10.5194/acp-10-66692010, 2010.

Paul, C. and Pohnert, G.: Production and role of volatile halogenated compounds from marine algae, Natural Product Reports, 28, 186-195, 2011.

Pfister, L., Selkirk, H. B., Starr, D. O., Rosenlof, K., and Newman, P. A.: A meteorological overview of the TC4 mission, J. Geophys. Res., 115, D00J12, doi:10.1029/2009JD013316, 2010.

Pisso, I., Haynes, P. H., and Law, K. S.: Emission location dependent ozone depletion potentials for very short-lived halogenated species, Atmos. Chem. Phys., 10, 12025-12036, doi:10.5194/acp-10-12025-2010, 2010.

Pyle, J. A., Ashfold, M. J., Harris, N. R. P., Robinson, A. D., Warwick, N. J., Carver, G. D., Gostlow, B., O’Brien, L. M., Manning, A. J., Phang, S. M., Yong, S. E., Leong, K. P., Ung, E. H., and Ong, S.: Bromoform in the tropical boundary layer of the Maritime Continent during OP3, Atmos. Chem. Phys., 11, 529-542, doi:10.5194/acp-11-529-2011, 2011.

Quack, B. and Wallace, D. W. R.: Air-sea flux of bromoform: Controls, rates, and implications, Global Biogeochem. Cy., 17, 1023, doi:10.1029/2002GB001890, 2003.

Salawitch, R. J., Weisenstein, D. K., Kovalenko, L. J., Sioris, C. E., Wennberg, P. O., Chance, K., Ko, M. K. W., and McLinden, C. A.: Sensitivity of ozone to bromine in the lower stratosphere, Geophys. Res. Lett., 32, L05811, doi:10.1029/2004GL021504, 2005.

Schauffler, S. M., Atlas, E. L., Blake, D. R., Flocke, F., Lueb, R. A., Lee-Taylor, J. M., Stroud, V., and Travnicek, W.: Distributions of brominated organic compounds in the troposphere and lower stratosphere, J. Geophys. Res.-Atmos., 104, 21513-21535, 1999.

Schofield, R., Fueglistaler, S., Wohltmann, I., and Rex, M.: Sensitivity of stratospheric $\mathrm{Br}_{\mathrm{y}}$ to uncertainties in very short lived substance emissions and atmospheric transport, Atmos. Chem. Phys., 11, 1379-1392, doi:10.5194/acp-11-1379-2011, 2011.

Toon, O. B., Starr, D. O., Jensen, E. J., Newman, P. A., Platnick, S., Schoeberl, M. R., Wennberg, P. O., Wofsy, S. C., Kurylo, M. J., Maring, H., Jucks, K. W., Craig, M. S., Vasques, M. F., Pfister, L., Rosenlof, K. H., Selkirk, H. B., Colarco, P. R., Kawa, S. R., Mace, G. G., Minnis, P., and Pickering, K. E.: Planning, implementation, and first results of the Tropical Composition, Cloud and Climate Coupling Experiment (TC4), J. Geophys. Res., 115, D00J04, doi:10.1029/2009JD013073, 2010.

Tost, H., Lawrence, M. G., Brühl, C., Jöckel, P., The GABRIEL Team, and The SCOUT-O3-DARWIN/ACTIVE Team: Uncertainties in atmospheric chemistry modelling due to convection parameterisations and subsequent scavenging, Atmos. Chem. Phys., 10, 1931-1951, doi:10.5194/acp-10-1931-2010, 2010.

Warwick, N. J., Pyle, J. A., Carver, G. D., Yang, X., Savage, N. H., O'Connor, F. M., and Cox, R. A.: Global modeling of biogenic bromocarbons, J. Geophys. Res.-Atmos., 111, D24305, doi:10.1029/2006JD007264, 2006.

Yokouchi, Y., Hasebe, F., Fujiwara, M., Takashima, H., Shiotani, M., Nishi, N., Kanaya, Y., Hashimoto, S., Fraser, P., ToomSauntry, D., Mukai, H., and Nojiri, Y.: Correlations and emission ratios among bromoform, dibromochloromethane, and dibromomethane in the atmosphere, J. Geophys. Res.-Atmos., 110 , 
D23309, doi:10.1029/2005JD006303, 2005.

Yung, Y. L., Pinto, J. P., Watson, R. T., and Sander, S. P.: Atmospheric Bromine And Ozone Perturbations In The Lower Stratosphere, J. Atmos. Sci., 37, 339-353, 1980.
Zhou, Y., Mao, H. T., Russo, R. S., Blake, D. R., Wingenter, O. W., Haase, K. B., Ambrose, J., Varner, R. K., Talbot, R., and Sive, B. C.: Bromoform and dibromomethane measurements in the seacoast region of New Hampshire, 2002-2004, J. Geophys. Res.-Atmos., 113, D08305, doi:10.1029/2007JD009103, 2008. 